\title{
Gender differences in the domains of job satisfaction: a questionnaire survey among doctors
}

\author{
Saad Ahmed Ali Jadoo ${ }^{*}$
}

\begin{abstract}
Background: The impact of gender differences in the labor market cannot be neglected when studying job satisfaction among doctors. This study aimed to assess the gender differences in a ten-items Warr-Cook-Wall (WCW) job satisfaction scale among Iraqi medical doctors.

Methods: A cross-sectional study was conducted between January and June 2014 in Iraq. The multistage sampling technique was recruited to collect the data from 20 health institutions. A total of 576 doctors returned the self-administered questionnaire (response rate $=87.3 \%$ ). Student $t$-test and the Pearson correlation tests were used to analyzing the data.

Results: Female doctors rated the overall job satisfaction index significantly higher than their peer male colleagues $(P<0.001)$. Findings of student t-test showed a significant gender difference; women doctors appeared more satisfied than men in the freedom to choose the method of working, satisfied with their colleagues and fellow workers, amount of responsibility given to them, income, opportunity to use their abilities, hours of work and the amount of variety in the job. In contrast, the Pearson correlation coefficient results indicated a high satisfaction among male doctors than females in terms of recognition for good work $(P=0.02)$ and the physical working condition $(P=0.04)$, respectively.
\end{abstract}

Conclusion: Analysis of data based on indices rather than the only overall job satisfaction appeared as an efficient method to understand gender differences. The possibility of increasing the representation of women in recognition and awards may raise the level of job satisfaction.

Keywords: Gender Differences, Warr-Cook-Wall (WCW), Job Satisfaction, Doctors, Domains, Recognition, Iraq

\section{Background}

The differences between male and female physicians in terms of job satisfaction have been discussed widely in the literature [16]. The gender gap for overall job satisfaction level was to favor women in some studies $[1,2]$ and is similar $[3,4]$ or favor the men in other studies [5]. Mora et al. [5] indicated that overall job satisfaction was the predominant approach in research; however, studying each domain of the job satisfaction scale alone may help to "understand the real satisfaction at the individual level." When considering the domain of workrelated income: it is widely reported as an essential indicator of job satisfaction, burnout, and turnover intention among healthcare professionals [6]. Significant income disparities; were seen among the gender; 'the gender pay gap has widened' [7]. Kumar et al. [8] reported that female doctors were often

*Correspondence: drsaadalezzi@gmail.com

${ }^{1}$ Department of Public Health, Faculty of Medicine, Bezmialem Vakif University, Istanbul, Turkey

Full list of author information is available at the end of the article. satisfied with lower income and minimum reimbursement. Khuwaja et al. [3] found that the 'workload,' 'relation with colleagues,' and 'autonomy' were significantly related domains with less satisfaction among female doctors. Goetz et al. [1] found that out of ten items Warr-Cook-Wall (WCW) job satisfaction scale, four domains; 'freedom of working method,' 'recognition for work,' 'hours of work' and 'amount of variety in the job' have been rated higher among woman doctors compare to men [1]. Van ham [9] found that 'lack of recognition' and 'heavy workload' were among the variables related to job dissatisfaction.

Working hours continued to be a severe factor influencing the continuity and productivity of work. Both efficiency and the quality of provided services reduced significantly with longer working hours [10]. Women doctors, especially the young age group, often prefer flexible workplaces in terms of working hours and the number of patients [11,12]. Van Hassel et al. [13] found that gender significantly affected working hours between male and female general practitioners (GPs); female GPs spent fewer hours at work than their peer male GPs. Practicing 
medicine is hard work and requires enough patience and endurance. Both gender and generation have an impact on choosing medicine as a future career and specialization. Sanfey et al. [14] found that women were significantly influenced by the decision to have a family than their men. Women are spending more time taking care of their children than staying in paid work [15]. Historically, the proportion of males attending medical schools was higher than in women. However, the reverse happened gradually over the last three decades [16]. Indeed, most of the barriers that prevented women from entering medicine did not exist now. Medical schools in the world, including the Arab region, have witnessed unprecedented proportions in the number of female students, and the percentage exceeded half in some universities [16,17]. Coinciding with the growing number of women graduates in medical schools and its consequences on the workforce market, further research to assess the impact of sex on overall job satisfaction and other domains of job satisfaction became inevitable. This study aimed to assess the gender differences in job satisfaction by surveying medical doctors currently working in Iraq.

\section{Methods}

Study Setting and Population

A cross-sectional study was conducted to test the gender differences in job satisfaction domains among medical doctors. Retrospective information retrieved from a previous project intended to test the job satisfaction and turnover intention among a national sample of Iraqi doctors where the design, sampling, and data collection have been reported in detail [6]. The sample size was calculated based on Fisher's formula to estimate a single proportion [18]. The standard deviation was set at a $95 \%$ confidence interval; prevalence assumed at $50 \%$ with the allowable margin of error of $5 \%$.

Fisher's formula: $\mathrm{N}=\left[\mathrm{Za}^{2} \mathrm{x} \mathrm{PXQ} /(\mathrm{M} . \mathrm{E} .)^{2}\right]$ gave a sample of six hundred respondents. The minimum sample size was rounded up to 660 when $10 \%$ of the minimum sample size added for "non-response, inappropriately filled or missing questionnaires." A multistage sampling technique used to collect the sample from twenty major general hospitals and medical centers covering the main five geographical regions in Iraq (north, west, south, central, and the capital city (Baghdad).

An average of thirty-three doctors per hospital selected randomly. In the current analysis, only gender differences among doctors were assessed and discussed. At the time of the study, all Iraqi physicians working in the selected hospitals and centers and willing to participate included. A well-trained team was recruited to collect the data between January and July 2014. All the eligible doctors received one copy of a self-administered questionnaire manually. The chief medical officers (CMO) and the hospital managers were excluded from this study. Finally, responses were received from 576 doctors.

\section{Measures}

All participants were asked to fill in the questionnaire in its two parts: (1) Sociodemographic factors such as age, gender, marital status, bearing children, and professional factors such as the presence of specialty, years of service, employment type, working hours and the opportunity for education and training. (2) Job satisfaction was measured with the previously validated version of the 10-item Warr-Cook-Wall (WCW) job satisfaction scale developed by Warr et al. [19]. The WCW instrument measures overall job satisfaction "Taking everything into consideration, how do you feel about your job?" and satisfaction with nine aspects of work with each item rated on a 7-point Likert scale ( $1=$ very dissatisfied to $7=$ very satisfied $)$. A higher overall mean score indicates higher job satisfaction". Cronbach's alpha coefficient of the job satisfaction scale was excellent (0.97). The questionnaire presented in the English language and test piloted among 20 physicians.

\section{Statistical Methods}

The "Statistical Package for Social Sciences (SPSS)" version 16.0 was recruited to analyze data. Data presented as mean (M) and standard deviation (SD). Descriptive analysis for sociodemographic performed. An independent-sample t-test was run to determine the significant differences between male and female doctors for the overall job satisfaction index and the nine individual indices hypothesized to configure job satisfaction in the WCW scale. T-test $t$ statistics used to compare the means of two distributions with unequal variances and unequal numbers of observations. Correlation analyses between genders were conducted using the method described by Fisher [20] and recently tested by Carvajal et al. (2018) [21]. The procedure depends on transforming the Pearson correlation coefficient values (r values) of the nine indices into $\mathrm{z}$ scores and determining the observed $\mathrm{z}$ test statistic. The formula, as shown below:

$\mathrm{Z}$ observed $=\left(\mathrm{z}_{\mathrm{mi}}-\mathrm{Z}_{\mathrm{wi}}\right) /\left(\right.$ square root of $\left[\left(1 / \mathrm{n}_{\mathrm{m}}-3\right)+\left(1 / \mathrm{n}_{\mathrm{w}}-3\right)\right]$

Where

$\mathrm{Z}_{\mathrm{mi}}=0.5[\ln (1+\mathrm{r})-\ln (1-\mathrm{r})]$

$\mathrm{Z}_{\mathrm{wi}}=0.5[\ln (1+\mathrm{r})-\ln (1-\mathrm{r})]$

Zmi was the male physicians' Pearson correlation coefficient for the $i$ th index;

$\mathrm{Z}_{\mathrm{wi}}$ was the female physicians' Pearson correlation coefficient for the $i$ th index;

$\mathrm{n}_{\mathrm{m}}$ was the number of male physicians in the sample;

$\mathrm{n}_{\mathrm{w}}$ was the number of female physicians in the sample; and

$i=1,2 \ldots, 10$ for the overall job satisfaction index, and the nine indices hypothesized to configure job satisfaction. The "ln" is the natural $\log$.

Then the statistical significances are estimated by checking the $\mathrm{Z}$ observed values with the corresponding critical values. Level of significance (two-tail tests) identified at $p \leq 0.05$. In the Pearson correlation coefficient the absolute values ( $r$ values) were categorized into three groups: (1) the values of less than 0.3 viewed as a weak link; (2) the values from 0.3 to 0.69 indicated of a moderate link; and (3) the values of 0.7 and above considered as indicative of a robust joint variation between the overall job satisfaction index and the nine indices.

\section{Results}

Descriptive analysis

Five hundred and seventy-six completed questionnaires were analyzed. Mean age $( \pm \mathrm{SD})$ was 40.43 years $( \pm 8.59)$, male 39.4 $( \pm 8.71)$, female $41.31( \pm 8.40)$. More than one-half of the participants $(310,53.8 \%)$ were women compared to (266, $46.2 \%)$ men. More women $(59.2 \%)$ than men $(40.8 \%)$ were married. The highest percent $(55.5 \%)$ of doctors with 
professional experience of more than ten years were women. More than half of doctors in the sample have a double work in the public and private sector $(37.7 \%$ for men and $62.3 \%$ for women).

Table 1 shows the sociodemographic factors in relation to gender $(\mathrm{n}=576)$

\begin{tabular}{llll}
\hline Variables & Male & $\begin{array}{l}\text { Female } \\
\mathrm{N}(\%)\end{array}$ & P-value \\
\hline Number of observations & $266(46.2)$ & $310(53.8)$ & - \\
$\begin{array}{l}\text { Marital status (married) } \\
\text { Bearing children }\end{array}$ & $151(40.8)$ & $219(59.2)$ & 0.001 \\
$\begin{array}{l}\text { Professional experience } \\
\text { of }>10 \text { years }\end{array}$ & $188(44.5)$ & $234(55.5)$ & 0.015 \\
$\begin{array}{l}\text { Specialist } \\
\text { Government and private }\end{array}$ & $112(48.9)$ & $117(51.1)$ & 0.306 \\
$\begin{array}{l}\text { Working more than 40 } \\
\text { hours/week }\end{array}$ & $132(49.4)$ & $135(50.6)$ & 0.155 \\
$\begin{array}{l}\text { Opportunities for } \\
\text { education and training }\end{array}$ & $132(41.8)$ & $184(58.2)$ & 0.023 \\
\hline
\end{tabular}

Indices

An independent-sample t-test was run to determine if there were differences in the job satisfaction scale between male and female doctors. Table 2 presents the means (M) and standard deviations (SD) of the overall job satisfaction index and the facet indices hypothesized to configure job satisfaction in the WCW scale.
The values of all ten indices were in the average range. "Freedom to choose the method of working" and "the opportunity to use your abilities" reported the top two index values. Physical working conditions appeared to be the lowest level of satisfaction followed by "the recognition you get for good work". Male doctors' overall level of satisfaction was lower than that of female doctors, and the difference was statistically significant. Higher levels for women also appeared for the facet indices, and all differences were significant except for physical working conditions and "the recognition you get for good work".

\section{Joint variation}

The estimated values of the Pearson correlation coefficients between "the overall job satisfaction index," and each of the nine facet indices is presented in Table 3. Three faced indices exhibited a strong joint variation; however, all showed a positive sign. "Freedom to choose the method of working," "hours of work" and "amount of variety in your job" recorded the highest values, while the income, your colleagues and fellow workers, and recognition you get for good work had the lowest values. Two of the facet indices exhibited significant differences at $<0.1$ and $<0.05$ between men and women doctors in their correlation with the overall satisfaction index of the same gender. The "physical working conditions" and "the recognition you get for good work" were higher for male than female doctors.

Table 2 Results of student t-test gender differences on 10-items Warr-Cook-Wall (WCW) job satisfaction scale (n=576)

\begin{tabular}{|c|c|c|c|c|c|c|c|}
\hline No & Job Satisfaction & $\begin{array}{l}\text { Both gender } \\
\text { Mean }(\underline{+} \mathrm{SD})\end{array}$ & $\begin{array}{l}\text { Male } \\
\text { Mean }( \pm \text { SD) }\end{array}$ & $\begin{array}{l}\text { Female } \\
\text { Mean }( \pm \text { SD }) \\
\end{array}$ & t. test & p-value & $\begin{array}{l}95 \% \text { CI } \\
\mathrm{L}-\mathrm{U}\end{array}$ \\
\hline & Number of observations & 576 & 266 & 310 & - & - & - \\
\hline 1 & Physical working conditions & $3.81(1.63)$ & $3.69(1.69)$ & $3.92(1.58)$ & 1.663 & 0.097 & $0.04-0.50$ \\
\hline 2 & Freedom to choose your method of working & $4.60(1.79)$ & $3.87(1.79)$ & $4.33(1.76)$ & 3.058 & 0.002 & $0.16-0.75$ \\
\hline 3 & Your colleagues and fellow workers & $4.26(1.61)$ & $4.09(1.65)$ & $4.41(1.57)$ & 2.393 & 0.017 & $0.06-0.59$ \\
\hline 4 & Recognition you get for good work & $3.89(1.62)$ & $3.77(1.66)$ & $3.99(1.59)$ & 1.592 & 0.112 & $0.05-0.48$ \\
\hline 5 & Amount of responsibility you are given & $4.22(1.72)$ & $3.84(1.74)$ & $4.69(1.59)$ & 6.063 & 0.000 & $0.57-1.12$ \\
\hline 6 & Your remuneration i.e., income & $4.40(1.70)$ & $4.15(1.79)$ & $4.62(1.58)$ & 3.336 & 0.001 & $0.19-0.75$ \\
\hline 7 & Opportunity to use your abilities & $4.54(1.69)$ & $4.21(1.78)$ & $4.81(1.56)$ & 4.336 & 0.000 & $0.33-0.89$ \\
\hline 8 & Your hours of work & $4.30(1.75)$ & $3.98(1.77)$ & $4.43(1.71)$ & 3.097 & 0.002 & $0.16-0.74$ \\
\hline 9 & Amount of variety in your job & $4.30(1.72)$ & $4.08(1.76)$ & $4.49(1.65)$ & 2.895 & 0.004 & $0.13-0.70$ \\
\hline 10 & $\begin{array}{l}\text { Taking everything into consideration, how do you } \\
\text { feel about your job? }\end{array}$ & $4.12(1.79)$ & $4.32(1.85)$ & $4.84(1.71)$ & 3.486 & 0.000 & $0.23-0.81$ \\
\hline
\end{tabular}

\section{Discussion}

To the best of researcher knowledge, this study was the first, which discussed the gender differences in domains of job satisfaction among medical doctors in Iraq and Arab region using the WCW questionnaire. In this study, the number of women doctors have slightly exceeded the number of men (ratio 1:0.9). Such findings are in line with the global trend of what is known as the "feminization of medicine" [12,16, 22]. No gender differences were seen in their professional experience, working hours per week, and having a specialty. However, significant gender differences existed with the type of employment and marital status. More women were married, bearing children, and having double work (public and private).
These findings may partly explain the engagement of many Iraqi women doctors in more than one work to secure the family's economic situation. However, according to the Iraqi Labor Law [23], the opportunity to obtain employment in the private sector is available to all doctors while maintaining the job in the public sector. Bedoya-Vaca et al. [22] reported that the choice of specialization among Ecuadorian women doctors significantly influenced by factors related to the role of women in child-rearing, economic sources, and social situations. Regarding the ten single aspects of the WCW job satisfaction scale, statistically significant gender differences were found in satisfaction with eight aspects, all of which were in favor of women (Table 2). Similar findings have been seen in earlier studies [1-3]. 
Table 3 Results of the Pearson correlation gender differences on 10-items Warr-Cook-Wall (WCW) job satisfaction scale (n=576)

\begin{tabular}{|c|c|c|c|c|c|c|c|}
\hline \multirow[t]{2}{*}{ Variables } & \multicolumn{3}{|c|}{$\begin{array}{l}\text { Pearson Correlation Coefficients } \\
\text { with an overall satisfaction index }\end{array}$} & \multicolumn{2}{|c|}{ Z scores } & \multirow[b]{2}{*}{$\begin{array}{l}Z_{\text {observed }} \\
\text { values }\end{array}$} & \multirow[b]{2}{*}{$\begin{array}{c}\text { Sig } \\
(2-\text { tailed })\end{array}$} \\
\hline & $\begin{array}{l}\text { Both } \\
\text { gender }\end{array}$ & $\begin{array}{l}\text { Male } \\
\text { Doctors }\end{array}$ & $\begin{array}{l}\text { Female } \\
\text { Doctors }\end{array}$ & $\begin{array}{l}\text { Male } \\
\text { Doctors }\end{array}$ & $\begin{array}{l}\text { Female } \\
\text { Doctors }\end{array}$ & & \\
\hline Number of observations & 576 & 266 & 310 & - & - & - & - \\
\hline Physical working conditions & $0.638^{* *}$ & 0.687 & 0.586 & 0.8423 & 0.6716 & 2.0418 & 0.041171 \\
\hline Freedom to choose your own method of working & 0.708 & 0.685 & 0.721 & 0.8385 & 0.9097 & 0.8516 & 0.394436 \\
\hline Your colleagues and fellow workers & 0.610 & 0.590 & 0.620 & 0.6777 & 0.7250 & 0.5657 & 0.571598 \\
\hline Recognition you get for good work & $0.622 * *$ & 0.680 & 0.562 & 0.8291 & 0.6358 & 2.3122 & 0.020767 \\
\hline Amount of responsibility you are given & 0.677 & 0.675 & 0.661 & 0.8199 & 0.7946 & 0.3026 & 0.762195 \\
\hline Your remuneration i.e. income & 0.595 & 0.604 & 0.569 & 0.6994 & 0.6460 & 0.6387 & 0.523018 \\
\hline Opportunity to use your abilities & 0.644 & 0.623 & 0.648 & 0.7299 & 0.7718 & 0.5011 & 0.616301 \\
\hline Your hours of work & 0.733 & 0.715 & 0.742 & 0.8973 & 0.9549 & 0.0576 & 0.954067 \\
\hline Amount of variety in your job & 0.761 & 0.771 & 0.743 & 1.0228 & 0.9571 & 0.0957 & 0.923759 \\
\hline
\end{tabular}

$* *$ Statistically significant between genders $(\mathrm{p} \leq 0.05)$

Comparing our findings with the study published by Goetz et al. [1], women doctors were significantly more satisfied than male doctors in three domains of 10-items WCW job satisfaction scale including 'freedom of working method,' 'hours of work' and 'amount of variety in a job' [1]. In fact, because of the socialization identity and the ability to absorb professional disillusionment, women were more prone to adapt to the idea of lower market expectations $[2,21,24]$ and to accept a lower level of remuneration and promotion compared to men [2,21,25].

Furthermore, Constant and Leger concluded that women doctors often provide fewer services than men [11]. However, Miao et al. [2] reported that in addition to a higher level of job satisfaction among women doctors than their men colleagues, they were also superior to men in terms of quality of provided healthcare services. Moreover, the Pearson correlation coefficient results showed that women were less satisfied with 'recognition they got for good work' and 'physical working condition' compared to men. Our results concur with the findings of the study carried out in the neighboring country (Saudi Arabia) [26]. It has appeared that in developing societies where the male gender has dominated, the working conditions are more likely to be hard for women with fewer chances of recognition. In contrast, our findings did not match the results of a study conducted in a developed country such as Switzerland, where the recognition was not affected by gender [1]. Iraqi doctors have been in an exceptional situation since the US-led invasion in early 2003. As a result of fighting operations and the subsequent migration and massive internal displacement, human resources for health lost many of its capabilities, and the work environment became unsafe. Many Iraq doctors have been kidnaped, killed, and forced to leave the job [6]. About 54.0\% of Iraqi doctors had the intention to leave because of the deteriorated security situation [6]. Ali jadoo et al. [27] found that about half of the surveyed Iraqi women doctors were exposed to physical, verbal, and sexual harassment. Consequently, the acute shortage of human resources indirectly led to accumulating work stress, burnout, and job dissatisfaction among resident doctors. [28]. Doctors were unable to cope with the results of weakness in the level of delivered health services.
The prevalence of emotional exhaustion was high (60\%) among the Iraqi doctors who were female, married, bearing children, and experienced unsafe workplaces [29]. A national study conducted in Turkey concluded that at night duties, the young female doctors with experience of fewer than five years were at high risk for workplace violence than their counterparts [30].

While this study attempts to provide a new and more indepth understanding of gender differences in terms of job satisfaction domains, we believe that further research about the gender differences in terms of burnout, work stress, and workplace violence would be of great benefit for the policymakers to improve the work environment. This study is subject to several limitations. First, although the multi-stage sampling technique was used to collect data at the national level, the deteriorating security situation in Iraq was an obstacle to access many health institutions. Most doctors are contacted in private clinics or homes. Moreover, the doctors' feelings, emotions and the level of satisfaction may change according to the changing of surrounding environments, especially if we know that this research has done during a critical period related to the Islamic State in Iraq and Syria (ISIS)-led invasion of most of the central and western regions of Iraq in 2014. Second, the English version of the WCW job satisfaction scale has test piloted before it has been delivered to participants; however, the language barrier may be another limitation because participants' native language is different (Arabic). Third, the self-reported data is more vulnerable to validity and reliability criticism. Finally, it is impossible to establish a causal relationship between the factors because the study design was crosssectional.

\section{Conclusion}

This study concluded that there was a gender difference on the ten items Warr-Cook-Wall (WCW) job satisfaction scale. Women doctors were more satisfied than men in most domains; however, they were unsatisfied with the recognition and the physical working conditions. The findings of this study add to the global efforts to understand the gender differences in job satisfaction. More attention should be given to assess women's 
dissatisfaction with the widened gender gap in terms of recognition awards for good work.

\section{Abbreviations}

CMO: Chief Medical Officers; WCW: Warr-Cook-Wall; SD: Standard Deviation; CI: Confidence Interval; ISIS: the Islamic State in Iraq and Syria

\section{Declarations}

\section{Acknowledgment}

We render our special thanks to all the Iraqi doctors and the paramedical staff for their working every day to serve their public and for their time and openness during the data collection.

\section{Funding}

The author received no financial support for the research, authorship, and/or publication of this article.

\section{Availability of data and materials}

Data will be available by emailing drsaadalezzi@gmail.com.

\section{Authors' contributions}

Saad Ahmed Ali Jadoo (SAAJ) is the principal investigator of this manuscript. SAAJ is the responsible author for the study concept, design, writing, reviewing, editing, and approving the manuscript in its final form. SAAJ has read and approved the final manuscript.

Ethics approval and consent to participate

We conducted the research following the Declaration of Helsinki, and the Ethical Committee of the Izmir University of Economics approved the protocol (Ref: B.30.2.IEU.0.05.05-020-014). Confidentiality was assured with signed informed consent.

Consent for publication

Not applicable

Competing interest

The author declares that he has no competing interests.

Author Details

${ }^{1}$ Department of Public Health, Faculty of Medicine, Bezmialem Vakif University, Istanbul, Turkey.

\section{Open Access}

This article is distributed under the terms of the Creative Commons $\begin{array}{llll}\text { Attribution } & 4.0 & \text { International License }\end{array}$ (http://creativecommons.org/licenses/by/4.0/), which permits unrestricted use, distribution, and reproduction in any medium, provided you give appropriate credit to the original author(s) and the source, provide a link to the Creative Commons license, and indicate if changes were made. The Creative Commons Public Domain Dedication waiver (http://creativecommons.org/publicdomain/zero/1.0/) applies to the data made available in this article unless otherwise stated.

Article Info

Received: 2 February 2020

Accepted: 09 July 2020

Published: 19 August 2020

\section{References}

1. Goetz K, Jossen M, Szecsenyi J, Rosemann T, Hahn K, Hess S. Job satisfaction of primary care physicians in Switzerland: an observational study. Fam Pract. 2016;33: 498-03.

2. Miao Y, Li L, Bian Y. Gender differences in job quality and job satisfaction among doctors in rural western China. BMC Health Serv Res.2017;17(1):848.

3. Khuwaja AK1, Qureshi R, Andrades M, Fatmi Z, Khuwaja NK. Comparison of job satisfaction and stress among male and female doctors in teaching hospitals of Karachi. J Rawalpindi Med Col 2009; 13:95-7.

4. Bahnassy AA, Saeed AA, Al-Kadhi Y, Al-Harbi J. Physicians' job satisfaction and its correlates in a Tertiary Medical Care Center, Riyadh, Saudi Arabia. Saudi J Med Med Sci 2016; 4:112-17.

5. Mora T, Ferrer-i-Carbonell A. The job satisfaction gender gap among young recent university graduates: Evidence from Catalonia. J Socio Econ 2009; 38: 581-89.

6. Ali Jadoo SA, Aljunid SM, Dastan I, Tawfeeq RS, Mustafa MA, Ganasegeran K, Aldubai SA. Job satisfaction and turnover intention among Iraqi doctors-a descriptive cross-sectional multicenter study. Hum Resour Health2015; 13:21.

7. Jena $A B$, Olenski AR, Blumenthal DM. Sex differences in physician salary in US public medical schools. JAMA Intern Med. 2016;176(9):1294-04.

8. Kumar R, Ahmed J, Shaikh BT, Hafeez R, Hafeez A. Job satisfaction among public health professionals working in public sector: a cross sectional study from Pakistan. Hum Resour Health. 2013;11(1):2.

9. Van Ham I, Verhoeven AA, Groenier KH, Groothoff JW, De Haan J. Job satisfaction among general practitioners: a systematic literature review. Eur J General Pract. 2006; 12:174-80.

10. Collewet M. and Sauermann J. Working hours and productivity, IZA discussion papers No 10722, Institute for the study of labor economics, 2017. http://ftp.iza.org/dp10722.pdf (accessed November 13, 2019).

11. Constant A, Leger PTL. Estimating differences between male and female physician service provision using panel data. Health Econ 2008; 17:1295-315

12. Russo G, Goncalves L, Craveiro I, Dussault G. Feminization of the medical workforce in low-income settings: findings from surveys in three African capital cities. Hum Resour Health. 2015; 13:64.

13. van Hassel D van der Velden L, de Bakker D, Batenburg R. Agerelated differences in working hours among male and female GPS: An SMS based time use study. Hum Resour Health 2017; 15(1):84.

14. Sanfey HA, Saalwachter-Schulman AR, Nyhof-Young JM, Eidelson B, Mann BD. Influences on medical student career choice: gender or generation? Arch Surg 2006;141(11):10861094.

15. Gravelle G, Hole AR. The work hours of GPs. Survey of English GPs. Br J Gen Pract. 2007; 57:96-100.

16. Mohamed NA, Abdulhadi NN, Al-Maniri AA, Al-Lawati NR, AlQasmi AM. The trend of feminization of doctors' workforce in Oman: is it a phenomenon that could rouse the health system? Hum Resour Health, 2018; 16:19.

17. Ali Jadoo SA, Dastan I, Jawdat A. Gender differences in the factors influencing the choice of future career among the final stage Turkish medical students. Journal of Ideas in Health $2020 ; 3(1): 145-51$.

18. Naing L, Winn T, Rusli BN. Practical issues in calculating the sample size for prevalence studies. Arch Orofac Sci. 2006; 1:914. 
19. Warr PJ, Cook J, Wall T. Scales for the measurement of some work attitudes and aspects of psychological well-being. J Occup Psychol 1979; 52: 129-48.

20. Fisher RA. 014: on the" probable error" of a coefficient of correlation deduced from a small sample. Metro.1921; 1:3-32.

21. Carvajal MJ, Popovici I, Hardigan PC. Gender differences in the measurement of pharmacists' job satisfaction. Hum Resour Health. 2018;16(1):33.

22. Bedoya-Vaca R, Derose KP, Romero-Sandoval N. Gender and physician specialization and practice settings in Ecuador: a qualitative study. BMC Health Serv Res.2016; 16:662.

23. International labour organization. Labour Law, 2015, Labour codes, general labour and employment acts, Iraq. http://www.ilo.org/dyn/natlex/natlex4.detail?p_lang=en\&p_isn=9 6652. (accessed March 17, 2019).

24. Bender KA, Donohue SM, Heywood JS. Job satisfaction and gender segregation. Oxf Econ Pap.2005;57(3):479-96.

25. Donohue SM, Heywood JS. Job satisfaction and gender: an expanded specification from the NLSY. Int. J. Manpow.2004; 25(2):211-38
26. Al-Rubaish AM, Rahim IA, Abumadini MS, Wosornu L. Job satisfaction among the academic staff of a Saudi university: an evaluative study. Journal of Family and Community Medicine 2009;16(3): 97-103.

27. Ali Jadoo SA, Torun P, Dastan I, Al-Samarrai M. Impact of conflict related and workplace related violence on job satisfaction among physicians from Iraq - a descriptive cross-sectional multicentre study. Journal of Ideas in Health 2018;1(1):14-22.

28. Kamimura A, Chen J, Nourian MM, Stoddard M, Al-Sarray A. Stress, depression, and job satisfaction among Physicians in Iraq. Diversity and Equality in Health and Care 2018; 15(2): 71-76.

29. Ali Jadoo SA, Dastan I, Al-Samarrai M, Yaseen S, Torun P. Predictors of emotional exhaustion among physicians from Iraq - a descriptive cross-sectional multicentre study. Journal of Ideas in Health 2018;1(2):42-9.

30. Pinar T, Acikel C, Pinar G, Karabulut E, Saygun M, Bariskin E, et al. Workplace violence in the health sector in Turkey: a national study. J Interpers Violence 2015; 37(15):2345-65. 